\title{
Parents' responses to predictive genetic testing in their children: report of a single case study
}

\author{
Susan Michie, Valerie McDonald, Martin Bobrow, Carole McKeown, \\ Theresa Marteau
}

\begin{abstract}
There is a widely held view among health professionals that predictive genetic testing of children for late onset diseases is not desirable clinical practice. Yet, little is known about the views of parents, or their responses, to predictive genetic testing in their children. Since such testing is being carried out in some genetic centres, the opportunity was taken to conduct a single case study of the parents of 2 and 4 year old sisters who were tested for the gene for familial adenomatous polyposis. Interviews before testing, after, and 15 months later showed a stable attitude, that parental responsibility included making decisions about such testing, and that the role of health professionals should be one of information giving rather than decision making. These parents had no regrets about having their children tested and reported no changes in their behaviour towards either the child who tested positively or the child who tested negatively. Using standardised scales, mood was found to be within the normal range both before and after testing in the mother and father. This case study is a first step towards systematic empirical studies determining the consequences of acquiescing to parents' requests for genetic testing in their children. (f Med Genet 1996;33:313-318)
\end{abstract}

Psychology and Genetics Research Group,

United Medical

Schools of Guy's \& St Thomas's

Hospitals,

Guy's Campus,

London SE1 9RT, UK

$S$ Michie

$\mathrm{V}$ McDonald

T Marteau

Department of

Medical Genetics

Addenbrooke's NHS

Trust,

Cambridge CB2 2QQ,

UK

M Bobrow

Clinical Genetics Unit, Birmingham

Maternity Hospital,

Birmingham B15 2TG

UK

C McKeown

Correspondence to: Dr Michie.

Received 3 October 1995 Revised version accepted for publication

16 November 1995
Key words: predictive genetic testing; children; psychological impact.

The question of whether predictive genetic testing should be available for children is the subject of much debate. ${ }^{12}$ Current practice and attitudes in Britain vary widely. ${ }^{3}$ Although some parents are asking for children to be tested, ${ }^{4}$ there is a variation of response to such requests, depending upon the view of the geneticist consulted. The consensus view of a working party set up by the Clinical Genetics Society to consider the issue of testing children at parental request was that "there should be a general presumption against such testing [where there is no direct health benefit to the child], although we recognise that circumstances may arise when testing could be appropriate." ${ }^{3}$

Surveys of parents' attitudes show them to have more favourable attitudes towards testing children than do health professionals. In Holland, for example, $41 \%$ of 70 people at risk for Huntington's disease thought that children under 18 should be allowed to have the tests. ${ }^{5}$ A UK study of parents from families carrying genetic translocations found that parents were generally in favour of testing being offered. ${ }^{6} \mathrm{Of}$ 211 children, 75 were untested. Parents of only eight of these children were against testing in childhood, with 16 undecided and 51 in favour. The few studies that have been conducted differ in age range and condition, making general conclusions difficult to draw.

One of the best ways to resolve this question is to collect evidence through systematic studies. $^{7}$ The questions of whether and how to respond to parents' requests for genetic testing for their children should be informed by data about the effects of such testing on (1) parents' attitudes and behaviour towards their children, (2) the children, and (3) wider family relationships. While there are no experimental or large scale studies to draw upon, some children are undergoing predictive genetic testing as part of routine genetic services and hence provide an opportunity for single case studies. In this paper, we describe the experiences of one set of parents who were interviewed during the conducting of a larger study. ${ }^{8}$ This larger multicentred study is investigating the psychological impact of predictive DNA testing for familial adenomatous polyposis (FAP) upon young people aged 10 and above and their parents. This age cut off reflects the lower age at which most clinicians feel it is appropriate to offer predictive testing, given that this is the age when bowel screening usually begins. Approval for the study was given by the relevant local research ethics committees.

At one of the genetics clinics participating in this prospective study, a couple requested DNA testing for their daughters, aged 2 and 4 years. Despite discussion of the potential problems that might arise, the couple remained adamant that this was what they wanted. The clinical geneticist agreed and asked that the family take part in the research study so that we could learn from their experiences. We report here the views of these parents before receiving DNA test results on their daughters, two weeks after receiving the results, and 15 months later.

The family

The father is affected with FAP and had an ileostomy and "bag" before meeting his wife. His father died from bowel cancer in his middle years because the condition was not diagnosed and treated early enough. The couple had discussed and agreed about the desirability of having their children tested before their children were conceived. Their daughters were aged 4 and 2 years at the time of testing. 


\section{Measures}

Mood was assessed psychometrically by four questionnaires which were given to parents to complete at the first and third interviews. These were:

(1) Short form of the Spielberger State-Trait Anxiety Inventory. ${ }^{9}$

(2) The depression scale of The Hospital Anxiety and Depression Scale. ${ }^{10}$

(3) Rosenberg self-esteem scale. ${ }^{11}$

(4) Impact of Event Scale, ${ }^{12}$ which measures subjective stress as expressed by intrusive thinking.

\section{Procedure}

The parents were informed about the current debate on genetic testing in children and asked to participate in our study. They agreed willingly and gave written consent. The parents were interviewed by a research genetic counsellor (VM) at home, together before testing and separately two weeks and 15 months after testing. The interviews were tape recorded and transcribed. The interview before testing covered questions about why the parents wanted their children to be tested, their understanding of the test results, how high or low risk results might affect them and their attitudes and behaviour towards their children, who they would tell, when and how they would tell their children, and their views about who should decide about testing. The interviews after testing covered how they were told and what they understood by the results, their reactions to the results, their behaviour towards the children, who they have told, when and how they would tell their children, and their views about having had the test results and about who should decide about testing.

\section{Analysis}

The transcripts were analysed thematically, informed by the results of an earlier study. ${ }^{8}$ The parts of the text that were relevant to the study questions were coded into categories, some of which were predetermined and some of which emerged from the texts.

\section{Results}

The parents were informed by the geneticist that one daughter had a high risk result on DNA analysis and the other a low risk result.

\section{PRE-TEST INTERVIEW}

The father did most of the talking. Unless indicated, the quotes were taken from the father's responses.

\section{Reasons for testing}

Seven reasons were given for wanting their daughters tested. Emphasis was placed upon the following.
(1) Using available technology, especially that which gives accurate results.

"There's no reason why not ... Because they've given us the opportunity to test."

(2) Avoiding the worry of uncertainty.

"It's great, you know one way or the other and then you can go from there ... the worst thing for me was not knowing and I don't want it to happen to my children ... when you don't know, it's a worry."

(3) Being able to support children by providing information they are seeking.

"At a point where, say she [daughter] was asking me and was old enough to understand what was going on and then I could tell her because you have to support your children and if you say 'I don't know' then you're giving them no support and you feel useless. From that point of view, I would worry that I was not given the information that I require, because it's my children."

(4) Avoiding resentment from children later in life.

"I was disgusted with my situation - that I knew nothing ... I wasn't told by my mother and I did have a go at my mother about that and it's something that she knew but she didn't tell me and it's something that I would never do to my children." "I would be horrified if I was not to know something that the doctors know and then later my child turned around to me and said 'why didn't you tell me'. That would hurt me more and give me pain, emotional pain, more than them having the operation."

(5) Helping prepare for the future.

"It also gives you time to sort out your own views and what you say to your child. Prepare yourself if you know for what's coming, but if you can support your child and gives you more time to sort our your own lives ... what's happening and obviously you can find out more information."

(6) Encouraging vigilance about preventative screening.

"If they turned around to me and said that there was a $95 \%$ chance they are going to get this, then I would contact the hospital quite regular, or the doctors or whatever and the age of .. when's the earliest you could screen, and from then on I would be very vigilant to make sure they did get screened."

(7) Parents having a right to decide.

"It's my right ... as long as my children are under 16 or whatever age it becomes their right to, it's my right to know that they are not going to hold back that information."

\section{Professional $v$ parental decision}

"They [at the genetics centre] said that they didn't like to do it [predictive testing]. They told us that, they sat there and we discussed it for a good hour - and we want the test done." 
The parents perceive the professionals' reason for not doing the test to be to prevent worry.

"Why worry about it for the next 10 years. It was their simple answer. Why give the information to you now, even if we know that we can, only for you to worry about it for the next ten years. But they were saying basically that that was a generalised opinion."

This professional view was challenged.

"They were saying, well you've a $50 \%$ chance they're not, so you've got half a worry. It just doesn't work like that. This is absolutely ridiculous. I say I think quite honestly, er, if we say we can handle this then it's for us to decide and us only and not by medical opinion that they tell us, and it's stupid, some doctor who or research doctor or whatever you want to say, can say to me 'we don't think you can handle it'. How do they know? They met me twice."

The parents saw themselves as the people who should be making the decision.

“... I think it's a personal choice whether you are told the results. I don't think it's the doctor who can actually turn around and give ... say 'this person cannot handle it'."

There was also a view that professionals may put research interests first.

"They got the information they wanted from me, with the eye tests and checked their research and then they turned around and basically they just forgot about us and I don't mind helping in research for other people, I'll do that anyway and to help, it's going to help my children if I give help with the research but when they just turn around and basically ... 'well, we have what we want, go away'."

\section{Anticipated reactions to test results}

(Mother) "We don't think of it in terms of 'they probably won't get it', we're thinking of it in terms of 'well they might get it' because we are aware that it gets passed on, so I think we ... already ... don't think in terms of 'they won't get it' and we're not going to be absolutely devastated if we're told they are because it won't be a bolt out of the blue, is it."

\section{Anticipated behaviour towards children}

Many questions were asked about the possible responses to different test results, and the father was very certain that their behaviour would not change towards their children whatever the outcome.

\section{Telling others}

"I probably wouldn't tell anybody because all you do, in the family, in my family, if you alarm people and we decided we want to know but they didn't decide so what's the point in alarming other people. ..."
Telling the children

The view about age of telling is that it depends on the child, but would be several years after the parents knew.

"When is the best time for that child or that child? Two different people, I mean it could be an 8 year old or a 10 year old, it just depends on how they go and obviously if you've got more time to think about it then the questions would be given, or the answers would be given at different times or more information and when you thought it was necessary.

When they are old enough to understand, they're sort of ... at the same time you start to think about sex education and so and things like that. When they're old enough to comprehend what's going on then I would give them the information they required because it's for them to decide."

Both parents had obviously thought a great deal both about when to tell and about how to tell.

"I wouldn't actually turn around and tell them 'you are a high risk' and so on because you have to be careful what you say because I mean you're talking about an age of 10 or 11 years old ... there is enough problems when you are a 10 or 11 year old girl ... I think I would give them enough information so they are alert to the problem."

(Mother) "If we have them tested and we are told the results, as accurately as can be, then we will bring them up when it crops up in conversation, leaning towards whichever way perhaps the decision has gone so that there is going to be no 'have a test done and a big realisation of something devastating at any one age', and we want to bring them up with the knowledge. ..."

\section{POST-TEST INTERVIEW: TWO WEEKS AFTER}

Reasons for testing

Even though the father was the articulate spokesperson before testing about why he wanted the children tested, in the interview after testing he suggested that it was the mother who was most keen for testing.

(Father) "She was more concerned about having it - the tests - done when it became available ... so I backed her all the way. As far as the doctor was concerned, we both wanted these tests doing. I wasn't bothered, to be quite honest. But I said [that I wanted it] because I had to back her up otherwise, if I'd said no, then there was a possibility [that the doctor wouldn't agree to test]."

\section{Professional $v$ parental decision}

There was still a strong view that it is parents, not professionals who should decide.

(Father) "Because we're both responsible adults, and - who actually guide their own lives, and our children's ... I don't have to be treated like a child, and to actually know the information and have it in my hands, 
and not in the doctors', then it's better for me. It actually means that if there's any cockups, at the hospital or anything, I know what's to be done."

"I'm the parent. There's no one worrying about it more than the parents. OK, doctors have got concern, but they've got concern for a lot of other people as well."

“I wouldn't advise anybody ... I think it's the parents who have to decide what they want. It's personal."

(Mother) "I thought, right, well if they can tell me now, I want to know. Before that, I couldn't know, so there was no point in dwelling on it, but from then on I wanted them tested. But other than that, I'm completely guided by them [the professionals]."

"I think it really is very much up to an individual ... I would just say, really, just sit down quietly and think how you're going to feel if they turn round and say 'This is the result, your child's high risk' how are you going to feel, or how do you think you'll feel? And then how do you think you'll feel if they say 'Your child is low risk', and then, how are you going to feel when you know that you could know?! . . . If you just sit and think about it for a while, a few days, or a few weeks, or even a few months - or longer until you are quite clear in your own mind that either (1) you can cope with the information, (2) you can't cope with it, or (3) you think, well what's the point of knowing, anyway. ... I think most people, with a few exceptions, are capable of making that decision."

\section{Reactions to test results}

There was immediate relief and little long term emotional impact for both parents.

(Father) "Relieved. Yes, that's the initial thing ... We were both resigned to the fact that there was high possibility of one or both - and it was just relief that we knew."

To the low risk result:

"Obviously, from the parental point of view, it's great ... She hasn't got problems, it's nice to know that there's one thing less to worry about in her lifetime."

To the high risk result:

"I would have been surprised if both of them would have got away with it. ... It's a shame she's going to have to go through something, one way or another."

(Mother) "Pleased that we finally knew, because I'd always wanted to know. ... I actually made a comment that I felt quite awful, because I wasn't devastated as I felt perhaps some people might think I should be. But just a bit sad that it hadn't worked out what I really would have liked, that was for them both to be low risk. Which is obviously what anyone would want. But yes, yes I think I was more pleased, that we finally knew, because I'd always - whenever it came up, which isn't really very often, it isn't something that's quite dominant in our lives whenever it was discussed or brought up I always thought, I wonder what it is, and I wish we could know. And, so, I was just pleased that finally I did know."

"I made the promise to myself that I would feel sad about it for a little while, and cry if I felt like crying, then that would be it. The tears would be dried and I would just - that would be it - they would never see a negative, sort of thought, about it again - if that's the right way to describe it. But I didn't even feel like that. I just thought, right, that's it now."

Getting the test results made the mother more relaxed about preventive screening.

"If we hadn't had that test done, I would have had them down there, on the doorstep I think, from the first age that they agree to do it [bowel screening] ... I feel more comfortable about it all now, anyway."

Neither parent had regrets about having had the tests done, and both were pleased about it.

\section{Behaviour towards children}

Both parents were certain that the different results had not altered and would not alter their behaviour to the children in any way, and they reported not worrying more about the daughter with the high risk result.

\section{Telling others}

Both parents had thought about this issue in advance and were still certain that they would not tell others about the results:

(Father) "Because, however hard people try, they let things slip. And once you tell one person and they bring somebody else in their confidence. And word goes round, and before you know it everybody else knows but the person who's got it. ... People don't think like I do, so they might start treating her [daughter with high risk result] different. I don't want that."

(Mother) "We did talk about this on the way home from the hospital. Well, actually we talked about it very briefly on the way, about what would happen if the results would go in different ways. ... And we've decided that they don't affect the way we feel about them, but they might affect the way other people feel about them, so, for that reason, because of the way the results fell, we decided that we would not tell anybody."

\section{Telling the children}

The parents had similar views about when and how to tell the children; the approach would be a gradual one, led by the children's developing interest and understanding. There was no certainty about exactly when and how the children would be told. They appreciated the time to prepare for it, and did not anticipate that the telling would be a problem. 
(Father) "I think you have to go with the flow ... I suppose I'll have an answer. I mean, I've got plenty of time to think about it. It's difficult, it's one of these - there's not a straight answer to it. I mean it depends on the set of circumstances and what's happening at the time."

(Mother) "I won't say there is an age. I think, we'll treat it like - I think I said to you - the last time when you were here, I wanted to know the results so that we could introduce it in a - gradual, almost, way ... so there was no big 'Sit down, I've got something to tell you'... And you can only tell them when they ask the questions ... if they're old enough to ask the question, they're old enough to know the answer. ... If she asks me something about it, then I'll answer it to what her capability of understanding is, and whatever age it is, so that she's always going to know without finding it coming as a big shock."

POST-TEST INTERVIEW: 15 MONTH FOLLOW UP At this later follow up, the views and reported experiences of both parents were virtually identical to those 15 months earlier.

\section{Reasons for testing}

The father maintained his previous view that having the information provided by testing would help him be a good parent.

(Father) "You have to be prepared, and you can't go walking into an exam without learning all the subjects you need to learn first and, it's the same in life. And if you've got all the information it makes it easier. Why make hard work for myself in years to come, when she asks that question, by not knowing. And she's looking at you and thinking 'bloody hell, you're my parent, why don't you know? You're meant to know the answers'."

The mother said she wanted to know because it was possible to know and because it would be helpful in being more aware of watching for signs in the daughter with high risk results.

\section{Parental $v$ professional decision}

The father was still angry about the way he had been treated by his doctor when he was younger, especially being denied information.

(Father) "... the rough justice that I had when I was younger, right, it was the fact that I never got tested when I was younger, and there was a lot of hassle and still, in my mind, I am peeved, right, by the way that my surgeon treated me and I've heard reports from several other people that he's the same with everybody else, ie he feels like he's acting like God, in effect that he won't give out all the information ..."

"I think quite honestly they love the power, these doctors! They hold onto the information and don't like to give it out. There's only been a change in law a few years ago to say that they had to show you your records. They didn't want to, because they like the power."

The parents still regarded the decision as to whether to have their children tested as an individual decision.

(Father) “I wouldn't advise anybody. I wouldn't presume to tell somebody how to run their life. The same way as I wouldn't expect other people to try and do it for me."

(Mother) "And this is what I said to them (the health professionals) before, when they were arguing whether or not we should have them tested, is I think you just know whether you're the type of person that can handle things. If you're a worrier, and what not, you just can't handle knowing, and you're best not knowing."

The mother considered that the decision was for either the parents or the child to make, and did not mention health professionals within this context.

(Mother) "Well if the child is very very young, like ours are, then I think the decision as to whether they are tested or not would lie with the parents. However, if they're older, if the child's already got into their teens ... then I think that then that decision lies with the child, and if that child wants the test done then fine, and if they don't, then that's fine."

She cited two advantages from the child's point of view for having testing: avoiding bowel examinations for those with low risk results and avoiding uncertainty.

\section{Reactions to test results}

Neither parent said that they felt any worry or guilt having had the results. The only emotion they reported was feeling a bit sad about the high risk result, the mother initially and the father at the back of his mind. They had no regrets. If the parents had been refused testing, the mother would not have let the issue drop. (Mother) “. . . and if they hadn't tested them then, I would have been on to them intermittently at a later date, asking them if they would reconsider having the tests done."

\section{Behaviour towards children}

Both parents reported that the test results had not influenced their feelings about or behaviour towards either child.

\section{Telling others}

Both parents did not want others in the family to know about the testing before their children knew. However, the mother's mother had asked after finding out about the hospital appointments and so both of the mother's parents were told and sworn to secrecy. They agreed with the reasons for not telling others and so far this confidentiality had been kept. 
The results of four measures of mood

\begin{tabular}{|c|c|c|c|c|}
\hline & \multicolumn{2}{|l|}{ Mother } & \multicolumn{2}{|l|}{ Father } \\
\hline & Pre-test & $\begin{array}{l}15 \text { months } \\
\text { post-test }\end{array}$ & Pre-test & $\begin{array}{l}15 \text { months } \\
\text { post-test }\end{array}$ \\
\hline Anxiety* & 37 & 23 & 27 & 20 \\
\hline Depressiont & 9 & 6 & 7 & 6 \\
\hline Self-esteem $\ddagger$ & 37 & 39 & 39 & 33 \\
\hline Intrusive thoughts $\int$ & 0 & 0 & 0 & 0 \\
\hline
\end{tabular}

* Scale range: $20-80$, higher scores denoting higher levels of state anxiety

† Scale range: $0-21$, higher scores denoting higher levels of depression.

¥ Scale range: $10-40$, higher scores denoting higher levels of
o Scale range: $0-35$, higher scores denoting greater intrusion

\section{Telling the children}

Both parents were clear about why they wanted to know and about their approach to telling the children. The children had not been told anything so far as they had not asked questions. The father anticipated that they would have told their children in about six or seven years time.

(Father) "We know that we can prepare ourselves for the inevitable questions, and not be put on the spot, now knowing ourselves, and not knowing what to say."

(Mother) “... as they get older and as we feel they're becoming more aware of things, we'll break it in just the way that you'd do - perhaps if you'd adopted a child."

“... I want it to just be a very slow, slow thing, so hopefully it will just eventually dawn on them, without any devastating effect of what's going on."

Psychometric assessment of mood

The results of the psychometric measures of mood are shown in the table. All of these measures were within the normal range. Anxiety appears to decrease after testing, but the significance of this cannot be established in a single case.

\section{Discussion}

These interviews show a certainty, clarity, and consensus between these parents about wanting predictive genetic testing for their children. They are clear about why they wanted predictive genetic testing and had thought through the possible outcomes and potential problems, for example, that one or both might be at high risk, whether to tell others the results, and how to tell the children. Their views were reported to be stable over the time before testing and appeared to be stable over the two week and 15 month periods after testing. Their anticipated reactions to the results appeared to be a good predictor of their short and long term reactions after testing.

There was a great deal of evidence of psychological preparation and the desire for time to prepare. There was evidence of anticipating the worst in order to avoid disappointment, a phenomenon that was found in our earlier study. ${ }^{8}$

Both parents are very definite and feel strongly about their right to decide about their children's testing. Although they are not antiprofessional about other questions and are quite happy to follow their advice on other health related matters, they do not feel that professionals have the relevant experience or right to make the decision. They have a view about the role and responsibilities of being a parent and consider that having knowledge about the children's risk status is important in allowing them to give support and the necessary information when it is requested.

For these parents, the decision by the clinical team to be guided by their request for testing seems to have done no harm, and appears to have been beneficial in providing certainty and increasing parental confidence. Predictive test results, whether positive or negative, have been found to reduce the distress associated with uncertainty in other high risk groups, those at risk of $\mathrm{HD}$ and those at risk of breast cancer. $^{51314}$ Although this study is limited by being a single case, the consistency of the results with those of other studies suggests a hypothesis that urgently needs addressing in controlled studies:

Complying with requests for predictive DNA testing (including pre- and post-test counselling) in parents wishing to reduce uncertainty about their children's future health is associated with good psychological outcomes regardless of the test results.

Susan Michie, Valerie McDonald, and Theresa Marteau are supported by The Wellcome Trust.

1 Michie S. Predictive genetic testing in children: paternalism or empiricism? In: Marteau TM, Richards MPM, eds. or empiricism? In: Marteau TM, Richards MPM, eds.
The troubled helix: social and psychological implications of the The troubled helix: social and psychological implications of the new human genetics.

2 Clarke A, Flinter F. The genetic testing of children: a clinical perspective. In: Marteau TM, Richards MPM, eds. The troubled helix: social and psychological implications of the new human genetics. Cambridge: Cambridge University Press, 1996:164-76.

3 Clinical Genetics Society. Report of the working party on the genetic testing of children (Clarke A, chairman). $\mathcal{F}$ Med Genet 1994;31:785-97.

4 Morris M, Tyler A, Lazarou L, Meredith L, Harper PS Problems in genetic prediction for Huntington's disease. Lancet 1989;ii:601-3.

5 Tibben A. On psychological effects of presymptomatic DNA-testing for Huntington's disease. PhD thesis, Rotterdam University, The Netherlands, 1993.

6 Barnes C. Genetic testing of children. Fourth European Conference of Psychosocial Aspects of Genetics, Heidelberg, Conferenc

7 Marteau TM. The genetic testing of children. $f$ Med Genet 1994;34:743.

8 Michie S, McDonald V, Marteau T. Understanding responses to predictive genetic testing: a grounded theory approach. Psychol Health (in press)

9 Marteau T, Bekker $H$. The development of a six-item shortform of the state scale of the Spielberger State-Trait Anxiety Inventory (STAI). Br f Clin Psychol 1992;31: 301-6.

10 Zigmond AS, Snaith RP. The hospital anxiety and depression scale. Acta Psychiatr Scand 1983;67:361-70.

11 Rosenberg M. Society and the adolescent self image. Princeton Princeton University Press, 1965.

12 Horowitz M, Wilner N, Alvarez W. Impact of event scale: a measure of subjective distress. Psychosom Med 1979;41: 209-18.

13 Wiggins $\mathrm{S}$, Whyte $\mathrm{P}$, Huggins $\mathrm{M}$, et al. The psychological consequences of predictive testing for Huntington's disconse. $N$ Engl f Med 1992;327:1401-5.

14 Lynch HT. DNA screening for breast/ovarian cancer susceptibility based on linked markers - a family study. Arch Intern Med 1993;153:1979-87. 